\title{
Editorial: Planning Support Systems
}

\author{
John Stillwell ${ }^{1}$
}

Received: 11 March 2015 / Accepted: 12 March 2015 /

Published online: 28 March 2015

(C) Springer Science+Business Media Dordrecht 2015

This special issue of the journal aims to provide a series of papers representing the state-of-the-art in terms of the development of planning support systems (PSS). Four contributions are included which illustrate not only different systems and applications but also the contextual drivers that underpin their development, such as technological changes including the emergence of cloud computing, and austerity measures that have pervaded public sector institutions as a consequence of national debt crises following the global recession. The applications exemplify the use of PSS in different thematic contexts in different parts of the world including Western Australia, Wyoming, the north of England and the Netherlands.

The first paper by Chris Pettit and colleagues provides an excellent example of the way in which one well-known desktop planning support system, What If? (Klosterman 2001), is being transformed to take advantage of the benefits of cloud computing and offer users the opportunity online to generate future land-use predictions under alternative scenarios. The new Online What If? (OWI) system is being developed as part of the Australian Urban Research Infrastructure Network (AURIN) initiative and the paper outlines one of the tools available from this workbench that enables maps to be produced that show the relative suitability of grid squares for different types of land use. The methodology is illustrated with a case study of the anticipated growth rate in the North West Metro Perth sub-region, in collaboration with the Western Australia State Government. The results of two scenarios - one focussed on employment generation and the other on environmental conservation - are investigated and a comparison of the simulations reveals that that even under the more restrictive assumptions of the latter scenario, the sub-region can accommodate the predicted population growth whilst not compromising the environmental considerations.

In the second paper, the focus moves from land-use planning per se to the relationship between infrastructure development, residential growth and the cost and efficiency of providing public services in Wyoming in the USA. Scott Lieske and his co-authors present a methodology that begins with a comparison of the population growth trends

John Stillwell

j.c.h.stillwell@leeds.ac.uk

1 University of Leeds, Leeds, UK 
over 20 years in parts of Sheridan County that have experienced different levels of investment in water infrastructure and that evaluates the implications of changing residential development for tax revenues and expenditure on services. The Scenario 360 module of the CommunityViz planning support tool is used to perform the calculations based on geographic data and the results of the modelling work indicate that much of the residential development associated with the Sheridan County water supply area is efficient when it comes to the provision of policing services.

Greater efficiency of service provision has become imperative as local governments in many countries have come under acute pressure to reduce expenditures and deliver services with less resources allocated from central governments. Austerity strategies and policy measures have been introduced in many countries around the world as a response to the global crisis and local government is in the forefront of those organisations having to shoulder the impact of these policies. In the USA, "states and local municipalities are switching roles with the federal government" (Davidson 2013, p. 1), providing employment and services in the gap left by the departure of the federal government from delivering a broad range of social welfare. In the UK, local government is one of the foremost casualties of the austerity measures introduced by the Coalition Government. A study by Hastings et al. (2013) estimated that local government spending in England was set to fall by nearly $30 \%$ between 2008 and 2015; and that cuts in expenditure have been systematically greater in more deprived local authorities than in more affluent ones. Reducing budgets whilst simultaneously safeguarding the level of essential public services as much as possible, requires thorough knowledge of cost effectiveness and its determinants.

One of the ways in which local authorities in the UK can maintain service provision under difficult financial circumstances is through the encouragement of members of the local community to undertake transactions with the local authority online through the internet rather than through face-to-face meetings with staff at council offices. This is one of the drivers behind the adoption of a web-based mapping system by Barnsley Metropolitan Borough Council as explained by Riley Marsden in the third paper in this issue. Barnsley, in the north of England, was the first local authority to adopt the MapInfo Stratus web mapping system and the author, a Geographic Information Officer working for the Council, reflects on the experience of commissioning and implementing the system. The paper explains the context and rationale for procurement, outlines the barriers to implementation and exemplifies the functionality of the system with downloads of the web interface as well as three case studies demonstrating the benefits of different applications - in asset management, providing the public with a mapping local data and enabling planning consultation.

The final paper in the series by Peter Pelzer and colleagues focuses on the use of PSS in supporting the collaboration between stakeholders during the process of planning in different contexts. The theoretical framework is that which captures the relationship between the planning task in hand, whatever that may be, and the PSS technology that is being used. One of the key accusations levelled at PSS is that, in many cases, they are never adopted in practice due to a range of bottlenecks as described a decade ago by Vonk et al. (2005). Consequently, ensuring that the technology is appropriate for the task remains an imperative and this paper assesses this socalled task-technology fit in four different planning contexts in the Netherlands using a PSS with two main components: the Maptable, a digital touch table, and 
CommunityViz, the software system developed within ArcGIS that provides various tools to analyse and visualise geographic data. The paper differs from previous papers in the issue by including qualitative feedback from the participants that enable the authors to identify the benefits but also some of the drawbacks associated with using the PSS to provide analytical or communication support for exploration, selection and negotiation tasks.

Each of these papers presents positive outcomes of the application of PSS in the different planning contexts in which the systems are being implemented and used. Collectively, they represent a statement that PSS are becoming of increasing value to practitioners and the final paper is one of an increasing number of studies (including, for example, Te Brömmelstroet 2010; Goodspeed 2013; Pelzer et al. 2014) that seek to develop a clearer assessment of PSS utility. This editor is very grateful to the authors concerned for agreeing to the request to contribute a paper in this issue in the first instance and, subsequently, for responding to the various rounds of correction and revision required to bring the special issue to fruition.

\section{References}

Davidson, P. (2013) State, local government finances humming again. USA Today, January 2. Available from: http://www.usatoday.com/story/money/business/2013/01/02/state-local-government-finances/1797293.

Goodspeed, R. (2013) Planning Support Systems for Spatial Planning Through Social Learning. PhD Thesis, Massachusetts Institute of Technology, Cambridge, Mass.

Hastings, A., Bailey, N., Besemer, K., Bramley, G., Gannon M. and Watkins, D. (2013) Coping with the cuts? Local government and poorer communities. JRF Programme Paper, Joseph Rowntree Foundation, York. Available at: http://www.jrf.org.uk/publications/coping-with-cuts.

Klosterman, R. (2001). The What If? Planning support system. In ESRI (Ed.), Planning support systems: integrating geographic information systems, models and visualisation tools. Redlands: ESRI Press.

Pelzer, P., Geertman, S., Van der Heijden, R., \& Rouwette, E. (2014). The added value of planning support systems: a practitioner's perspective. Computers Environments and Urban Systems, 48, 16-27.

Te Brömmelstroet, M. (2010) Making Planning Support Systems Matter: Improving the use of Planning Support Systems for integrated land use and transport strategy-making. $\mathrm{PhD}$ Thesis, University of Amsterdam, Amsterdam.

Vonk, G., Geertman, S., \& Schot, P. (2005). Bottlenecks blocking widespread usage of planning support systems. Environment and Planning A, 37, 909-924. 